\title{
Article
}

\section{Assessing Students' Ability to Trace Matter in Dynamic Systems in Cell Biology}

\author{
Christopher D. Wilson, Charles W. Anderson, Merle Heidemann, John E. Merrill, \\ Brett W. Merritt, Gail Richmond, Duncan F. Sibley, and Joyce M. Parker
}

Division of Science and Mathematics Education, Michigan State University, East Lansing, MI 48824

Submitted February 13, 2006; Accepted July 5, 2006

Monitoring Editor: Marshall Sundberg

\begin{abstract}
College-level biology courses contain many complex processes that are often taught and learned as detailed narratives. These processes can be better understood by perceiving them as dynamic systems that are governed by common fundamental principles. Conservation of matter is such a principle, and thus tracing matter is an essential step in learning to reason about biological processes. We present here multiple-choice questions that measure students' ability and inclination to trace matter through photosynthesis and cellular respiration. Data associated with each question come from students in a large undergraduate biology course that was undergoing a shift in instructional strategy toward making fundamental principles (such as tracing matter) a central theme. We also present findings from interviews with students in the course. Our data indicate that 1) many students are not using tracing matter as a tool to reason about biological processes, 2) students have particular difficulties tracing matter between systems and have a persistent tendency to interconvert matter and energy, and 3) instructional changes seem to be effective in promoting application of the tracing matter principle. Using these items as diagnostic tools allows instructors to be proactive in addressing students' misconceptions and ineffective reasoning.
\end{abstract}

\section{INTRODUCTION}

Reasoning in biology is being able to apply fundamental principles and rules to complex dynamic systems. This article is about measuring students' inclination and ability to apply fundamental principles about conservation of matter to the biological processes of photosynthesis and respiration. We consistently see evidence that this essential practice is absent from students' reasoning. For example, after instruction on photosynthesis and cellular respiration, undergraduate students in a large introductory biology course for science majors were asked to predict the change in dry mass of $1.5 \mathrm{~g}$ of radish seeds placed in a dark closet, with water, for $1 \mathrm{wk}$. The radish seed image in Figure 3 accompanied the question. Table 1 shows the range of students' initial responses (delivered via personal response systems ["clickers"]) and their second response to the question after discussing the problem with their peers.

DOI: $10.1187 /$ cbe.06-02-0142

Address correspondence to: John E. Merrill (merrill3@msu.edu).
The correct answer is "<1.5 g." Cellular respiration converted the chemical potential energy in the bonds of glucose molecules into usable energy in the form of ATP and released $\mathrm{CO}_{2}$ and $\mathrm{H}_{2} \mathrm{O}$ (lost mass); no photosynthesis occurs in the dark to replace the mass lost as $\mathrm{CO}_{2}$. In this example, following the principle of conservation of matter through this system leads the student to the correct answer. However, many students fail to use this principle when reasoning within biology. The results in Table 1 suggest that some students were even persuaded that their correct initial responses were wrong!

The content of college-level biology includes many complex processes that are often taught and learned as detailed narratives. That is, instructors recount existing knowledge about science that students interpret as series of loosely connected facts. For example, a narrative description of the conversion of sunlight to chemical energy might be as follows: "The absorption of light energy in the thylakoid membrane of the chloroplast takes place at groupings of chlorophylls and other pigments, proteins, and assorted small molecules, together forming a photosystem. The various photosystem pigments form the antenna complex, which 
Table 1. Percentage of students selecting each response option

\begin{tabular}{lcc}
\hline & Initial response (\%) & After discussion (\%) \\
\hline$>1.5 \mathrm{~g}$ & 38 & 49 \\
About $1.5 \mathrm{~g}$ & 32 & 27 \\
$<1.5 \mathrm{~g}^{\mathrm{a}}$ & 30 & 24 \\
\hline
\end{tabular}

${ }^{\text {a }}$ Correct answer.

harvests light energy, photons. The photons are passed to a special chlorophyll a in the middle of the reaction center, where the light reactions of photosynthesis begin." However, a more powerful approach to these processes is to view, teach, and learn them as dynamic systems to which fundamental principles apply. Such an approach provides ways of analyzing disparate processes from a common perspective. A key first step in understanding biological processes from this perspective is learning how to trace matter by following inputs and outputs. When we refer to dynamic systems in this article, we are almost exclusively talking about open systems that exchange matter and energy across defined boundaries. These boundaries may define the systems of interest as an organelle or a cell, or as larger systems such as organisms or ecosystems.

Tracing matter within and between systems is fundamental to a scientific perspective across disciplines:

- Chemistry explains mass balance and predicts changes in ions, molecules, and compounds during chemical reactions using balanced chemical equations.

- In the earth sciences, tracing matter through cycles is a way of organizing global processes. We trace elements, ions, molecules, and minerals through the processes of the rock cycle. Carbon atoms and carbon-containing molecules, compounds, ions, and minerals are traced through the biosphere, atmosphere, hydrosphere, and lithosphere. Water molecules are traced through the hydrologic cycle.

- One of the fundamental tenets of biology is that sense can be made of the complexity of the biosphere by viewing it as a set of interrelated systems that can range in size from the subcellular to the ecosystems level. We can trace matter and energy within these systems to understand them individually and between these systems to understand their interdependence.

- Among the fundamental principles useful in analyzing biological systems, tracing matter has been and remains a fruitful means of study. Calvin and Benson followed the fate of ${ }^{14} \mathrm{C}$-labeled compounds to elucidate the metabolic pathway that bears their name. Currently, studies measure the capability of trees to take up carbon dioxide in response to elevated atmospheric levels (Korner et al., 2005).

Tracing matter can also help students make sense of the complexities of biology, giving them a common way of analyzing disparate systems and finding patterns in details. This approach to teaching and learning about systems, although not new, is not well established in science education. The Project 2061 Benchmarks (American Association for the Advancement of Science, 1993) identify understanding sys- tems as a common theme that crosses the disciplines of science. They cite "detailed attention to inputs and outputs" as part of that understanding (p. 262). Furthermore, Ben-Zvi Assaraf and Orion (2005) identify eight characteristics of systems thinking, two of which are "the ability to identify the components of a system and processes" and "the ability to organize the systems' components and processes within a framework of relationships."

We think that tracing matter is a simple, particularly powerful organizing principle for college-level biology. Tracing matter can help students make sense of multistep processes presented by instructors and textbooks. For example, in two widely used introductory textbooks (Freeman, 2004; Campbell and Reece, 2004) 16-17 intermediates are shown between glucose and carbon dioxide along with 10 proteins involved in electron transport in the presentation of cellular respiration. This amount of detail can be overwhelming to students, and even those students who can master it have nothing transferable to bring to related systems. In contrast, tracing elements such as carbon and oxygen through these processes helps students organize and prioritize these details. An understanding based on tracing matter can also help them make sense of other metabolic processes, such as photosynthesis and the cycling of carbon through ecosystems.

We know from research at the K-12 and college levels that the ability to trace matter through simple physical and chemical changes is a hard-won accomplishment, especially for transformations between gases and solid or liquid substances (Novick and Nussbaum, 1981; Carey, 1985; Stavy, 1990; Bar and Travis, 1991; Hesse and Anderson, 1992; Driver et al., 1994; Gomez Crespo et al., 1995; Pozo and Gomez Crespo, 2005). Students need to recognize gases as forms of matter with mass and chemical identities; they need to master key elements of the atomic molecular theory of matter and its applications. They need to recognize mass as a fundamental measure of the amount of matter (Smith et al., 2007). These foundational understandings are necessary, but not sufficient, for students to use a matter-tracing strategy in reasoning about living systems.

In this article, we report on the first steps in using tracing matter as a theme for making sense of introductory biology. We present a number of simple application questions (Bloom, 1956) that assess students' ability and inclination to trace matter through the processes of cellular respiration and photosynthesis, accompanied by data collected across three semesters. The application questions that we developed in our research serve two important functions. First, they can be used to identify patterns in students' reasoning about biological systems. Our work indicates that students' difficulties fall into three general categories: 1) students interconvert matter and energy, 2) students lose track of matter when it becomes a gas, and 3) students do not follow matter and therefore do not catch obvious errors in their thinking. Second, these questions can be used as tools to measure the effectiveness of instructional practices aimed at improving students' ability to trace matter in metabolism.

\section{MATERIALS AND METHODS}

Our goal was to develop multiple-choice questions in which each distractor represents a typical conceptual barrier that students 
encounter when tracing matter through metabolic processes. The steps listed below show our design approach.

- Identified simple, familiar contexts involving organisms gaining or losing weight (mass).

- Asked students in introductory biology courses for science majors or a capstone course for senior secondary science teacher candidates (all science majors) to explain the weight gain or loss in each context in an essay format after instruction.

- Interviewed eight randomly chosen students in the biology class on their understanding of this content. The interviews were video- and audiotaped, transcribed, and analyzed by looking for instances and patterns related to the students' inclination and ability to trace matter.

- Developed distractors for multiple-choice questions based on patterns in students' open-ended responses.

- Used the multiple-choice questions in introductory biology courses for science majors on pretests and exams after instruction.

This research took place at a large public university and focused on an introductory biology course required for majors in the College of Natural Science, plus many students in the Colleges of Agriculture, Natural Resources, and Engineering. The course has a general chemistry prerequisite. Enrollment is approximately 1600-1800 students per year, in lecture sections of 350-500 each. A companion laboratory course is optional.

\section{RESULTS}

\section{Item Development}

The following results are divided into five groups of questions that focus on different aspects of metabolism in photosynthesizing and respiring organisms.

- Group 1. Application Questions on Weight Loss in Respiring Organisms

- Group 2. Application Questions on Tracing Matter through Photosynthesis and Cellular Respiration

- Group 3. Application Questions on Weight Gain in Photosynthesizing Organisms

- Group 4. Application Questions Involving Interpretation of Complex Data

- Group 5. Application Questions Involving Both Matter and Energy

Group 1. Application Questions on Weight Loss in Respiring Organisms

The first set of questions asks students to trace matter during weight loss in respiring organisms. We began the process of item development by asking the following question in essay format to one class of senior science teacher candidates ( $\mathrm{n}=$ 19) and one class of students in a senior physiology class ( $n=14)$ : Jared, the Subway man, lost a lot of weight eating a low-calorie diet. Where did all the fat/mass go? Thoroughly explain your answer.

Sample student responses to this item are shown below and are categorized in Table 2.

Best answer:

"The fat went through some metabolic processes and was converted into sugar. The sugar was used in respiration and was given off in the forms of $\mathrm{CO}_{2}$ and $\mathrm{H}_{2} \mathrm{O}$ and heat (and energy for other human processes). Some may have been given off as waste (urine and feces)."

\footnotetext{
${ }^{1}$ Even the single best student answer contained an incorrect matterto-matter conversion.
}

Table 2. Common responses to the "Jared" weight-loss essay question $(\mathrm{n}=33)$

\begin{tabular}{|c|c|c|}
\hline Category & Frequency & $\%$ \\
\hline \multicolumn{3}{|l|}{ Correct identification of products } \\
\hline $\begin{array}{l}\text { Fat converted to glucose, which is used in } \\
\text { respiration }\end{array}$ & 1 & 3 \\
\hline \multicolumn{3}{|l|}{$\mathrm{CO}_{2}+\mathrm{H}_{2} \mathrm{O}$ produced } \\
\hline \multicolumn{3}{|l|}{ Correct, but incomplete } \\
\hline $\begin{array}{l}\text { Mentions respiration without identifying } \\
\text { products }\end{array}$ & 4 & 12 \\
\hline \multicolumn{3}{|l|}{$\begin{array}{l}\text { Exhaled, or in atmosphere, without } \\
\text { identifying products }\end{array}$} \\
\hline Excreted & 3 & 9 \\
\hline $\begin{array}{l}\text { Fat converted to energy, burned or used as } \\
\text { fuel; no products named }\end{array}$ & 28 & 85 \\
\hline \multicolumn{3}{|l|}{ Use the nature of fat as the explanation } \\
\hline Fat is glycogen & 6 & 18 \\
\hline \multicolumn{3}{|l|}{ Fat is stored energy } \\
\hline \multicolumn{3}{|l|}{ Don't lose fat cells } \\
\hline Incorrect matter-to-matter conversions & 8 & 24 \\
\hline Fat to muscle & & \\
\hline Polysaccharides to ketones & & \\
\hline
\end{tabular}

Totals do not sum to 33 because some students used more than one idea in their responses.

Correct but no products named: "He exhaled it.... His system began breaking down the fat stores for energy uses. The by-product/waste products of this get put in his blood stream, passed into his lungs, and was exhaled."

Excreted:

"When the energy is extracted and used, the waste products are expelled from the body."

"The fat was also deposited out of his system through feces and excretion of sweat."

Fat converted to energy, burned, or used as fuel-no products named:

"The fat was converted into useable energy and burned by muscle contraction for movement."

"I'm assuming that much of his fat was used up by his body for energy to compensate for his lowered calorie intake."

"The fat was metabolized and used for energy in the body."

Used the nature of fat as the explanation:

"I'm not sure, but isn't fat a stored form of energy? ... The fat would be burned off."

"Your body is born with a certain amount of fat cells, therefore he did not technically lose any fat cells, he just lost mass."

Incorrect matter-to-matter conversions:

"As he ran out of energy from the food he was ingesting, his body began to break the bonds in his adipose cells to mobilize polysaccharides. These polysaccharides were broken down into ketones, which were used to fuel his body."

From the responses in Table 2, we developed distractors for multiple-choice items built around the same and similar contexts. The first two contexts ask students to trace matter in heterotrophs through the process of cellular respiration. We used several different wordings, all of which yielded 
similar results with different groups of students taking an introductory biology course for science majors. The third context deals with respiration in plants. In each context, one distractor is meant to identify students who interconvert matter and energy. The additional distractors allow students to choose erroneous products of respiration that are solids while ignoring the actual gaseous products, carbon dioxide (and water).

Figure 1 shows the results from using these items in large introductory biology courses and illustrates the pervasiveness of students' not tracing matter. The data shown in the figure also illustrate that we see consistent problems in different semesters. It should be noted that all of the multiple-choice items discussed in this article in some way oversimplify the science underlying these systems, but these oversimplifications are not why students are getting the items wrong - it is the practice of tracing matter within and between systems that is absent from students' reasoning.

Group 2. Application Questions on Tracing Matter through Photosynthesis and Cellular Respiration

The next item is an expanded version of the radish question discussed in the introduction, this time in the context of a potted geranium. The item requires the student to trace matter between photosynthesis and cellular respiration.
Item development began with the following open-ended question being asked to 66 undergraduate students: A potted geranium plant sits in a windowsill, absorbing sunlight. After I put this plant in a dark closet for a few days (but keeping it watered as needed), will it weigh more or less (discounting the weight of the water) than before I put it in the closet?

Sample student responses to this item are shown below and are categorized in Table 3.

Weighs less-respiration:

"The plant will weigh less because it will be going through cellular respiration. During cellular respiration $\mathrm{CO}_{2}$ (mass) is given off, therefore the plant weighs less."

\section{Weighs less-breakdown:}

"It is lacking the sunlight for photosynthesis so therefore it has to start relying on the energy already in its roots and essentially would be breaking down its own mass."

\section{Weighs less-no photosynthesis:}

"There was no sunlight energy coming into the plant making energy. Without the energy source from the sun, the plant will decrease in weight."

Weighs less-no photosynthesis, so no respiration:

"Without light [the plant] will not be able to produce glucose or finish the cycle and go on to cell respiration, so there will be less products than if you had left it in the light."

Context 1. You have a friend who lost 15 pounds of fat on a diet. Where did the fat/mass go (how was it lost)? or

Jared, the Subway ${ }^{\circledR}$ man, lost a lot of weight eating a low calorie diet. Where did all the fat/mass go?

Context 2. The emperor penguins of Antarctica live on a diet of fish and crustaceans obtained from the cold Antarctic seawaters. During their annual breeding cycle, however, they migrate across the frozen continent to their breeding grounds 50 miles away from the sea (and 50 miles away from their source of food). For over 2 months the male emperor penguins care for and incubate the eggs while the females return to the sea to feed. During this time the male penguin can lose up to $50 \%$ of its biomass (by dry weight). Where did this biomass go?

Context 3. Three batches of radish seeds, each with a starting weight of $1.5 \mathrm{~g}$ (dry), were placed in Petri dishes and provided only with light or water or both, as shown in the photo. After 1 week, the material in each dish was dried and weighed. The results are shown below. Where did the mass go that was lost by the seedling in the "No-light, Water" treatment?

The radish seed image in Figure 3 accompanied this question.

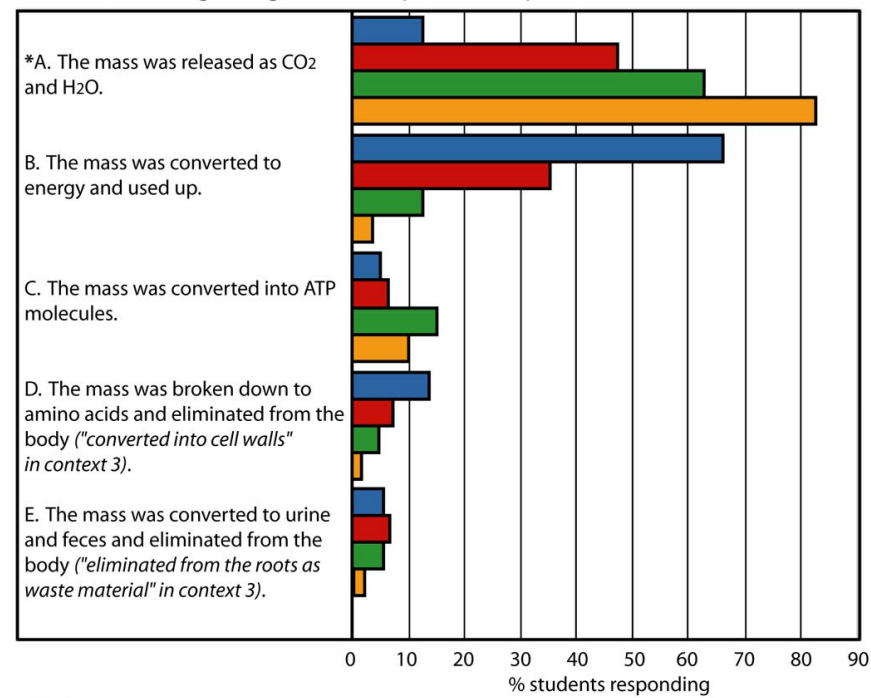

Pre-Instruction (context 1), Semester 1, $\mathrm{n}=141$

Post-Instruction (context 3), Semester 1, $n=14$ $\square$
Post-Instruction (context 1), Semester $1, n=153$ Post-Instruction (context 2), Semester $2, n=370$
Figure 1. Group 1 application questions about weight loss in animals and plants along with the percentage of students choosing each response. Data from summer and fall 2005. 
Weighs more-dark reaction:

"The Calvin Cycle can still function in the absence of light. Carbon fixation still takes places and the plant gains weight by incorporating the carbons."

Weighs more-no respiration:

"The organic materials that are needed to go through cellular respiration would just continue to accumulate, since there would be no sugar available for cellular respiration to actually occur. The build-up of the organic materials would cause an increase in weight."

\section{No difference:}

"The plant will weigh exactly the same because mass is never created nor destroyed."

"After several days in the closet, the plant should weigh nearly the same. No matter enters or leaves the plant."

As before, the distractors for a multiple-choice item were written based on the patterns in students' open-ended responses shown in Table 3 . The resulting item, along with student data from 370 students in the introductory biology course, are shown in Figure 2. This question was developed and used during the second semester of this project, and therefore only posttest data from that semester are reported here.

\section{Group 3. Application Questions on Weight Gain in Photo- synthesizing Organisms}

The next set of questions (Figure 3) deals with weight gain in plants via photosynthesis. The first context, the growth of a tree from a seedling, is based on the Private Universe scenario (Schneps and Sadler, 1988), which illustrates the common misconception of mass gain in plants not being attributed to the intake of carbon via $\mathrm{CO}_{2}$. The radish seed context is based on the work of Ebert-May et al. (2003) and builds upon the radish clicker question discussed in the Introduction. The same distractors were used for each context with similar results. The first two distractors draw on students' desire to account for the mass gain as coming from solid or liquid substances and on the common usage of plant "food" to designate nutrients absorbed via the roots. The last distractor draws on students' propensity to interconvert energy and matter. As before, distractors for these items were developed from patterns in student ideas in open-ended items.

Table 3. Common responses to the geranium metabolism essay question $(\mathrm{n}=66)$

\begin{tabular}{|c|c|c|c|}
\hline & Category & Frequency & $\%$ \\
\hline \multirow{6}{*}{$\begin{array}{l}\text { Weigh less } \\
\qquad(\mathrm{n}=49 ; 74.2 \%)\end{array}$} & & & \\
\hline & Did not give reason & 8 & 12.1 \\
\hline & Respiration & 13 & 19.7 \\
\hline & Breakdown & 10 & 15.2 \\
\hline & No photosynthesis & 10 & 15.2 \\
\hline & $\begin{array}{l}\text { No photosynthesis } \\
\text { so no respiration }\end{array}$ & 8 & 12.1 \\
\hline \multirow{3}{*}{$\begin{array}{l}\text { Weigh more } \\
\qquad(\mathrm{n}=12 ; 18.2 \%)\end{array}$} & Did not give reason & 3 & 4.5 \\
\hline & Dark reactions & 6 & 9.1 \\
\hline & No respiration & 3 & 4.5 \\
\hline \multirow{2}{*}{$\begin{array}{l}\text { No difference } \\
\qquad(\mathrm{n}=5 ; 7.6 \%)\end{array}$} & & 5 & 7.6 \\
\hline & Total & 66 & 100 \\
\hline
\end{tabular}

Group 4. Application Questions Involving Interpretation of Complex Data

The next set of questions (Figure 4) assesses students' ability to use knowledge of inputs and outputs to make sense of fairly complex data. Two versions of the question are shown along with student responses from an introductory biology course for science majors. The question can be reworked to fit any of the subprocesses of photosynthesis or respiration. Because these application questions require knowledge of the stages of respiration, the data presented here are from after instruction only.

\section{Group 5. Application Questions Involving Both Matter and Energy}

The final group of items involves energy transformations and highlights students' persistent tendency to interconvert matter and energy. Figure 5 shows student data from one of these items, which required students to explain how respiring organisms obtain energy from food. This question was developed and used during the second semester of this project, and so only posttest data from that semester are reported here.

These multiple-choice questions indicate that many students fail to use tracing matter or energy as a sense-making strategy. Some students do not make a distinction between chemical reactions that yield energy and mass being converted into energy. Others conserve energy, but look for answers that involve liquids or solids, overlooking gases. In interviews we found that this lack of inclination or ability to trace matter meant that students were unable to catch obvious errors in their thinking, as shown in the next section.

\section{Clinical Interviews}

Clinical interviews conducted with students in the course revealed consistent patterns in students' use of tracing matter as a sense-making tool. Most students showed no desire to trace matter within or between systems. For example, when asked about the inputs and outputs of photosynthesis and cellular respiration, Susan replied, "In photosynthesis [coming in are] $\mathrm{CO}_{2}$, starch or glucose, coming out is oxy-

A potted geranium plant sits in a windowsill, absorbing sunlight. After I put this plant in a dark closet for a few days (but keeping it watered as needed), will it weigh more or less (discounting the weight of the water) than before I put it in the closet?

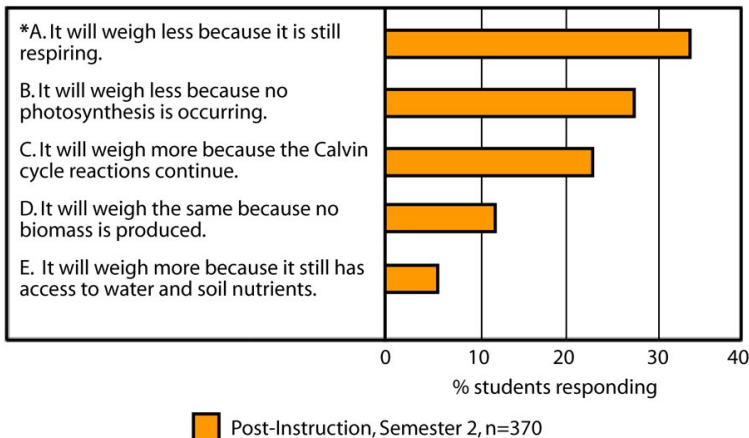

Figure 2. Group 2 multiple-choice item requiring students to trace matter through photosynthesis and cellular respiration. Data from fall 2005. This item was not used in pretests or in earlier semesters. 
gen, water and energy. In cellular respiration, I think it's just oxygen, energy and water coming in, it gives off glucose and starch." Susan was clearly not concerned that the carbon inputs and outputs were inconsistent in either system. Similarly, within photosynthesis, Todd described $\mathrm{CO}_{2}$ entering the chloroplast and being broken down in the light reactions but not moving to or entering the Calvin cycle: "The light goes in, and the $\mathrm{CO}_{2}$ is broken down, the electron acceptor is at each end that produces ATP. It's kind of like the electron transport chain in cellular respiration except this comes first. And then, they use that to power the Calvin cycle that produces glucose." Without the sense-making tool of tracing matter, Susan and Todd based their responses on imperfect memorized representations.

Conversely, a few students did seem to use the tracing matter principle as a sense-making tool. For example, while filling in labels on a diagram of photosynthesis, Mark had forgotten some of the narrative details of the process but sought to understand the system by tracing matter. When stuck trying to think of the Calvin cycle outputs, Mark commented, "There must be some carbon compound [coming out], we've got $\mathrm{CO}_{2}$ coming in, I'm not quite sure," illustrating systems-level thinking and application of the tracing matter rule. Other students, such as Lamar, demonstrated the ability to trace matter between systems when describing the products of photosynthesis: "The oxygen is just given off into the atmosphere, and also I think that can be used as the oxygen in cellular respiration. The 6-carbon sugar is the glucose needed for glycolysis in cellular respiration ... $\mathrm{CO}_{2}$ [from cellular respiration] would be given off into the atmosphere or recycled back and used in photosynthesis."

In summary, the interviews revealed the same patterns as we saw in the students' responses to both the open-ended and multiple-choice items. Most of the students, like Susan, were inconsistent in accounting for all the matter in their explanations and in using an "accounting system" based on matter to evaluate their explanations.

\section{DISCUSSION}

Although we consistently observed that students were not tracing matter through these systems, this result is not entirely inevitable. In response to this finding, several instructional changes were made in the large introductory biology
Context 1. A mature maple tree can have a mass of 1 ton or more (dry mass, after removing the water), yet it starts from a seed that weighs less than $1 \mathrm{gram}$. Which of the following processes contributes the most to this huge increase in biomass?

Context 2. Three batches of radish seeds, each with a starting weight of $1.5 \mathrm{~g}$ (dry), were placed in Petri dishes and provided only with light or water or both, as shown in the photo. After 1 week, the material in each dish was dried and weighed. The results are shown below.

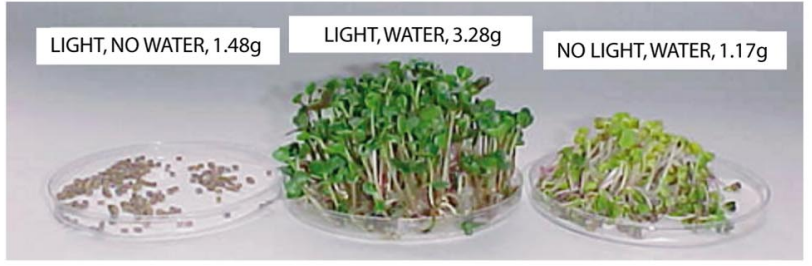

Which of the following processes contributed the most to the increased biomass of the "light, water" treatment?

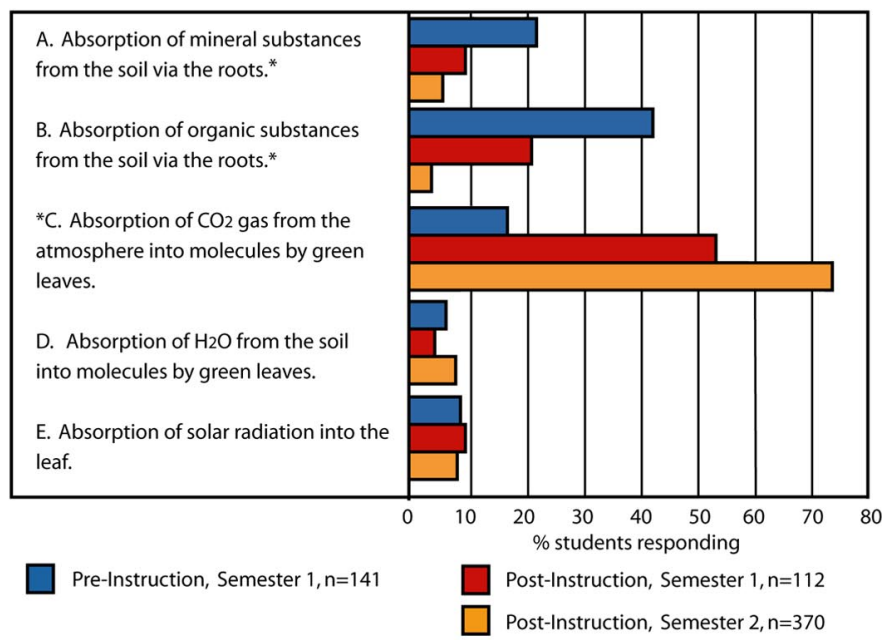

* "from the soil" was not included in the foils for Context 2
Figure 3. Group 3 items about weight gain in plants along with the percentage of students choosing each response. Data from summer and fall 2005. 
course (from which our multiple-choice data in Figures 1-5 were obtained), making tracing matter more central and giving students more opportunities to apply this principle. These changes are part of ongoing research that is continuing to refine this approach from semester to semester and have included the following:

- Textbook readings required before the lecture that cover the basic principles, followed by lectures focused on application of these principles to natural systems.

- Online homework questions using the LON-CAPA (The Learning Online Network with CAPA, 2004; www.loncapa.org) assessment system completed before lecture to assess required textbook content.

- Use of personal response clicker questions throughout the lecture that require students to apply their understanding and make predictions at the systems level. Mazur's Peer Instruction model (Mazur, 1997) was applied at this stage to encourage student discussion and to help develop conceptual understanding. Mazur's Peer Instruction model aims to address the problems associated with large-group instruction. In large classes, Mazur asserts that it is hard to provide opportunities for students to practice reasoning and receive feedback in class because interactions between students and teacher are limited. To address this, Mazur offers a three-step instructional model: 1) key ideas that the instruction must address are identified, 2) conceptual questions for these key ideas are identified, and 3) classroom time is devoted to demonstration in combination with the administration of concept tests. We see the clicker activities in our instruction as being analogous to Mazur's concept tests. With many of the clicker questions, students first individually respond to the question and then discuss the reasoning for their responses with their peers before being prompted to answer the same or a similar question again. The basis for this pedagogical move is the idea that two students might come to the class with different knowledge of the topic in question. The sharing of this knowledge can lead to students' constructing new understandings (or, as we found with the radish question described in the Introduction, new misunderstandings).

- Use of the items described in this article in a formative assessment cycle as a benchmark for measuring student progress.
Figure 4. Two Group 4 items requiring students to apply their knowledge of inputs and outputs to making sense of complex data. Data from summer and fall 2005 .
A research group has discovered an organism with cells that contain a previously undescribed organelle. They isolate a large quantity of these organelles by homogenization and differential fractionation by centrifugation. Next, they do some tests on the isolated organelle to see if it is involved in any major metabolic reactions. They incubate the organelles for a brief period of time and determine changes in the amount of various substances in the suspending solution. (Note: you can assume that various starting substrate materials for the pathways are provided in sufficient quantity by the researchers.) The results are:

Context 1.

Glucose

$\mathrm{CO} 2$

$\mathrm{O} 2$

ATP

$\mathrm{NADH}$

No change
Increase
No change
Increase
Increase

Context 2

\section{Glucose No change}

$\mathrm{CO} 2 \quad$ No change

$\mathrm{O} 2 \quad$ Increase

ATP Increase

$\mathrm{NADH} \quad$ No change

Based on this analysis, which metabolic process do you conclude is taking place in this organelle? Results from Context 1:

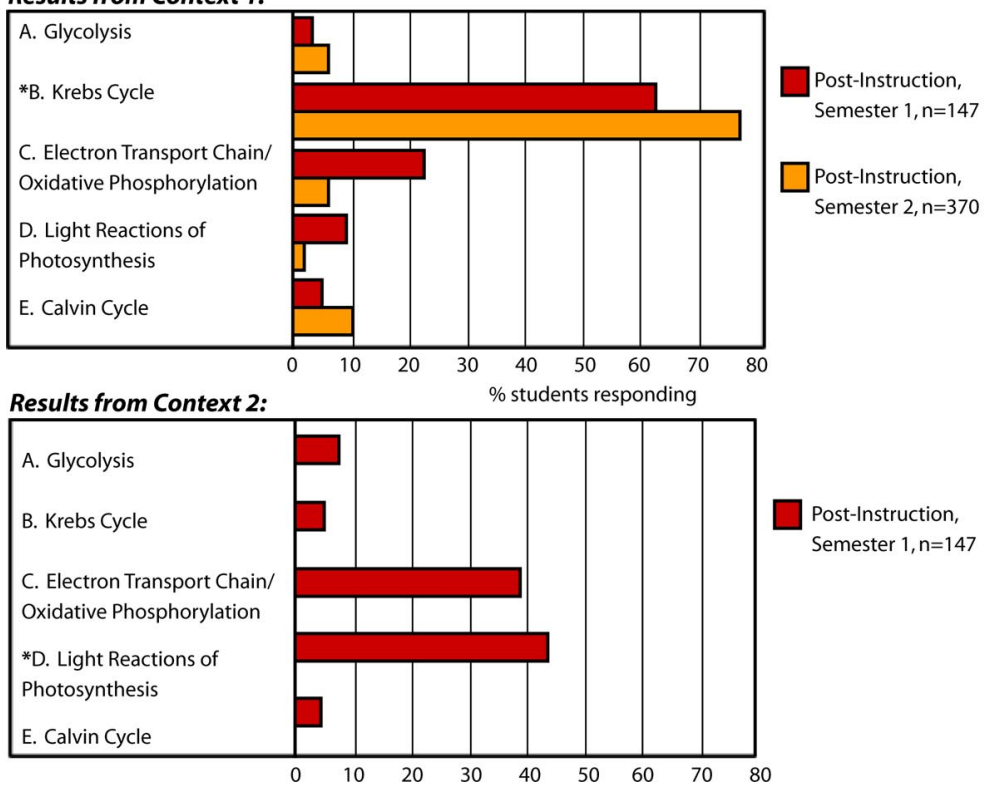


- Instruction that makes explicit the importance of tracing matter. For example, students are repeatedly encouraged to consider "what goes in, what comes out, and what the energy relationships are." This is elaborated by showing how to trace matter and energy and by discussing "energy management molecules" (e.g., ATP and NADH).

Our efforts to implement these instructional changes from semester to semester and to use these questions as benchmarks for measuring progress in helping students to take a systems approach to biology by tracing matter have produced some positive results (Figures 1 and 3), but it is clear from the data that we still have some significant challenges to meet, especially when it comes to tracing matter between systems (e.g., Figure 2) and to overcoming persistent matter-energy transformation misconceptions (Figure 5).

\section{CONCLUSIONS AND IMPLICATIONS}

Previous researchers have identified many student misconceptions about the processes of cellular respiration and photosynthesis (Driver et al., 1994). These misconceptions are summarized below. Our framework allows us to group these conceptual difficulties into a single category that may be addressed by an emphasis on tracing matter. In addition, it allows us to anticipate misconceptions related to other concepts.

Most of the previous research on this type of reasoning and related misconceptions was conducted with $\mathrm{K}-12$ students, but the same seems to be true of older students. Anderson et al. (1990) found that nonmajor students in a biology course were not committed to conserving matter when describing and defining photosynthesis, respiration, or food for plants and animals. Driver et al. (1994) report that both Barker (1985) working with 8- to 17-yr-old students and Driver et al. (1984) working with 15-yr-old students found that most of those students who attempted to explain where the biomass of plants comes from stated that it came from the absorption of water and nutrients via the roots. Barker (1985) suggests that this is not a deeply held belief but an

You eat a grape high in glucose content. How could a glucose molecule from the grape provide energy to move your little finger?

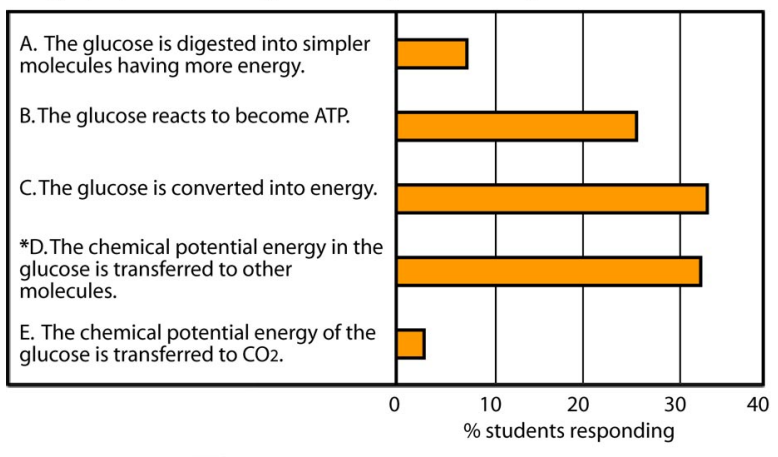

Post-Instruction, Semester $2, n=370$

Figure 5. One Group 5 item requiring students to explain how respiring organisms obtain energy from food. Data from fall 2005. This item was not used in pretests or in earlier semesters. on-the-spot response to a new question. "Plants were thought to grow and this was accepted at its face value rather than interpreted in terms of where additional material comes from" (Driver et al., 1994, p. 39). Either way, students are not approaching the question with a desire to explain the source of carbon, hydrogen, and oxygen molecules that make up the biomass of a plant. They state, "The universal and very persistent intuitive conception, identified in all studies with subjects of all ages, is that plants get their food from their environment, specifically from the soil" (p. 30). Driver et al. (1994) also report on the work of Leach et al. (1992) in which few 16-yr-olds applied conservation of matter to photosynthesis, respiration, and decay, and many did not distinguish between matter and energy. This problem is exacerbated when substances are invisible. In particular, the idea that gases have weight is problematic for students. Brook and Driver (1989) as reported in Driver et al. (1994) found that even at age 16, two-thirds of students think that air has no weight or even negative weight. Driver et al. (1994) go on to report on several studies that indicate "an intuitive disbelief in weight increase and growth due mainly to the incorporation of matter from a gas" (p. 32). These findings at the $\mathrm{K}-12$ level illustrate that students are rarely progressing to the undergraduate level with a set of sensemaking strategies that can be applied across a range of systems. Our results certainly confirm this to be the case. It is therefore essential that the focus of introductory undergraduate biology education is as much on understanding and using fundamental scientific principles as it is on learning the characteristics of particular systems.

The work presented here illustrates that reforming undergraduate science education cannot proceed by merely changing the content, or modifying the instruction, but rather must involve both reconceptualizing what it means to understand the content, and reframing the instruction accordingly. In helping students learn how to use the tracing matter principle, instructors must be clear and explicit in the need to account for matter, and to be consistent in applying the rule across different topics. For example, in addition to cellular respiration, the tracing matter principle can be usefully applied to understanding cell division, transcription and translation, and cell signaling. The questions presented here are necessary tools in helping students progress from being memorizers of elaborate and detailed narrative accounts to being analyzers and pattern finders. We encourage other researchers and instructors to use simple questions such as ours to distinguish between students who are unaware of basic principles from those who are unable to apply them. Modifying instruction based on such distinctions promises to be an effective approach to helping students to use their scientific understanding to effectively question and reason about the natural world.

The items in this article represent part of the products of an ongoing research project at Michigan State University focused on developing Diagnostic Question Clusters designed to measure and diagnose undergraduate student understanding of dynamic biological and geological processes. Once completed, the question clusters will be made available via the online LON-CAPA system (The Learning Online Network with CAPA, 2004; www.lon-capa.org) and published in scholarly journals. Anyone interested in this project 
or its products are encouraged to contact us for more information.

\section{ACKNOWLEDGMENTS}

We are grateful to Tammy Long and Mark Urban-Lurain for discussions and comments on the manuscript. We also acknowledge the dedicated participation of Diane Ebert-May, Heejun Lim, and Ron Patterson. This research was supported by National Science Foundation Grant DUE-0243126, National Science Foundation Cooperative Agreement EHR 0314866, and Carnegie Corporation Grant B7458.

\section{REFERENCES}

American Association for the Advancement of Science, Project 2061 (1993). Benchmarks for Science Literacy, New York: Oxford University Press.

Anderson, C., Sheldon, T., and Dubay, J. (1990). The effects of instruction on college nonmajors' conceptions of respiration and photosynthesis. J. Res. Sci. Teach. 27, 761-776.

Bar, V., and Travis, A. S. (1991). Children's views concerning phase changes. J. Res. Sci. Teach. 28, 363-382.

Barker, M. (1985). Teaching and learning about photosynthesis. Science Education Research Unit, Working Papers 220-9. University of Waikato, Hamilton, New Zealand.

Ben-Zvi Assaraf, O., and Orion, N. (2005). Development of system thinking skills in the context of Earth system education. J. Res. Sci. Teach. 42, 518-560.

Bloom, B. S. (ed.) (1956). Taxonomy of educational objectives: the classification of educational goals. In: Handbook 1. Cognitive Domain, New York: McKay.

Brook, A., and Driver, R. (1989). Progression in science: the development of pupils' understanding of air across the range 5-16 years. Centre for Studies in Science and Mathematics Education, University of Leeds, Leeds, United Kingdom.

Campbell, N. A., and Reece, J. B. (2004). Biology, 7th ed., San Francisco, CA: Benjamin Cummings.

Carey, S. (1985). Conceptual Change in Childhood, Cambridge, MA: MIT Press.

Driver, R., Child, D., Gott, R., Head, J., Johnson, S., Worsley, C., and Wylie, F. (1984). Science in Schools at Age 15, Report No. 2. Assess- ment of Performance Unit, Department of Education and Science, London: Her Majesty's Stationary Office.

Driver, R., Squires, A., Rushworth, P., and Wood-Robinson, V. (1994). Making Sense of Secondary Science: Research into Children's Ideas, New York: Routledge.

Ebert-May, D., Batzli, J., and Lim, H. (2003). Disciplinary research strategies for assessment of learning. Bioscience 53, 1221-1228.

Freeman, S. (2004). Biological Science, 2nd ed., Upper Saddle River, NJ: Prentice Hall.

Gomez Crespo, M. A., Pozo, J. I., and Sanz, A. (1995). Students' ideas on conservation of matter: effects of expertise and context variables. Sci. Educ. 79, 77-93.

Hesse, J., and Anderson, C. W. (1992). Students conceptions of chemical change. J. Res. Sci. Teach. 29, 277-299.

Korner, C., Asshoff, R., Bignucolo, O., Hattenschwiler, S., Keel, S. G., Pelaez-Riedl, S., Pepin, S., Siegwolf, R.T.W., and Zotz, G. (2005). Carbon flux and growth in mature deciduous forest trees exposed to elevated CO2. Science 309, 1360-1362.

Leach, J., Driver, R., Scott, P., and Wood-Robinson, C. (1992). Progression in conceptual understanding of ecological concepts by pupils aged 5-16. Centre for Studies in Science and Mathematics Education, University of Leeds, Leeds, United Kingdom.

Mazur, E. (1997). Peer Instruction, Upper Saddle River, NJ: Prentice Hall.

Novick, S., and Nussbaum, J. (1981). Pupils' understanding of the particulate nature of matter: a cross-age study. Sci. Educ. 65, 187196.

Pozo, J. I., and Gomez Crespo, M. A. (2005). The embodied nature of implicit theories: the consistency of ideas about the nature of matter. Cogn. Instruct. 23, 351-387.

Schneps, M. H., and Sadler, P. M. (1988). A Private Universe, New York: Annenberg/CPB. http://www.learner.org/resources/ series28.html (accessed 7 February 2006).

Smith, C., Wiser, M., Anderson, C. W., and Krajcik, J. Implications of research on children's learning for assessment: matter and atomic molecular theory. Measurement: Interdisciplinary Research and Perspectives (in press).

Stavy, R. (1990). Children's conceptions of changes in the state of matter: from liquid (or solid) to gas. J. Res. Sci. Teach. 27, 247-266.

The Learning Online Network with CAPA (2004). LON-CAPA Home Page. www.lon-capa.org (accessed 7 February 2006). 